\title{
Ein Bericht über die Ansprüche des Königs Alfons auf den deutschen Thron.
}

Von

\section{Adolf Fanta.}

Unter den Miscellanea des vaticanischen Archivs befindet sich ein Heft von 6 Folien in Kleinoctav, welche von einer Hand des 13. Jahrhunderts mit einem Berichte über die ron dem magister Rudolf von Pongibonsi geltend gewachten Ansprüche des Königs Alfons von Castilien auf den deutschen Thron ausgefüllt wurden. Wie aus dem Berichte hervorgeht, haben wir es nicht mit den von dem Magister selbst dem Papste eingereichten Artikeln zu thun, sondern mit einem Protokoll, das am päpstlichen Hofe, und zwar zu Viterbo ${ }^{1}$ ), über die Aussagen des castilischen Gesandten aufgenommen und dem Papste mitgetheilt wurde. Der Name des Papstes wird nicht genannt; aus dem Umstande aber, dass Alexander IV. und Urban IV. als Vorgänger genannt werden, ergibt sich, dass dieser Bericht für Papst Clemens IV. bestimmt war; dieser aber hatte seinen Aufenthalt zu Viterbo vom 30. April 1266 bis zu seinem Tode.

Eine genauere Datirung des Berichtes wird möglich, wenn wir das, was der zweitletzte Artikel besagt, mit einem Briefe des Papstes an König Alfons vom 9. Mai 1267 vergleichen ${ }^{8}$ ). Nach dem Berichte erbot sich Rudolf, das von ihm vorgebrachte durch Zeugenaussagen in Deutschland, Italien, Spanien, Frankreich und an der römischen Curie selbst zu beweisen. Er lehnte es aber ab, mit seinen Beweisen gleich jetzt herrorzutreten. Diese sollen durch das Bekenntniss der gegnerischen Partei, durch Briefe und Zeugenaussagen geliefert werden infra dilationes magnitudini, gravitati, qualitati et quantitati tanti et talis negotii congruentes. Gerade darüber aber beklagt sich der Brief

1) in civitate isfa Viterbiensi heisst es einmal bei Gelegenbeit einer Ver. handlung vor Alexander IV. 2) Potthast Reg. 20002 bei Raynald Annales ecclesiastici a, a, 1267. 
des Papstes an König Alfons. Darnach stellten die Gesandten Richards das Verlangen, dass der castilische Gesandte nicht mehr berücksichtigt werden solle ut pote cum idem magister solis assertionibus nudis insisteret nec ad probanda quae asserebat litieras rel aliud exhiberet. Nach dem Berichte erklärte Rudolf: quod non astringit se ad viam specialem probationis. Mit directer Bezugnahme auf diesen Bericht schreibt Clemens IV., dass Rudolf sich erboten habe assertiones suas super quibus etiam articulos certos exhibuit, in Alemannia, Francia, Hispania et Italia nec non in nostra curia probaturum infra dilationes tanto et tali negotio congruentes. Der Bericht also fällt in das Jahr 1267 und spielt in die Verhandlungen hinein, für welche der Freitag nach dem Dreikönigsfeste 1267 von Clemens IV. als Termin angesetzt war. Damals wurde, wie wir aus demselben Briefe erfahren, auch von Seiten des Gesandten Richards ein Bericht vorgelegt, doch scheint sich dieser nicht erhalten zu haben.

Auf die Wichtigkeit des Berichtes in besonderer Ausführung hinzuweisen, balte ich nicht für nöthig. Ueber die Ansprüche, welche Alfons und Richard auf den deutschen Thron erhoben, sind wir durch dic bekannte Bulle Urban IV. vom 31. August 1263 unterrichtet 1 ). Diese Znsammenfassung der Ansprüche beider Prätendenten ist offenbar auf Grund von Berichten entstanden, welche die beiden Parteien damals, sowie im Jahre 1267 eingereicht haben; der Bericht über die Ausprūche des Königs Alfons von 1263 dürfte aber mit den von Rudolf im Jahre 1267 vorgebrachten Allegationen inhaltlich sich so ziemlich gedeckt haben, wie aus einem Vergleiche unseres Berichtes mit den entsprechenden Stellen des Briefes von 1263 herrorgeht ${ }^{2}$ ). So wie hier von Wahlfürsten die Rede ist qui sunt septem numero, so wird die Siebenzahl der Kurfürsten auch in unserem Berichte vorausgesetzt. Diese Anschauung ist jedenfalls ron beiden Parteien

1) Potthast Reg. 18685 bei Rainald Ann. eccl. an $1269 \$ 53-60$.

2) Um die Allegationen Rudolfs in ihrer ganzen Schärfe zu erfassen, ist ein genauer Vergleich derselben mit dem, was in dem Briefe Urbans $\$ 57-60$ steht, nöthig. Ganz decken sich die Briefe and Berichte inhaltlich natürlich nicht. Wir lesen so manches im Berichte, was im Briefe fehlt und umgekehrt. Dort, wo sie sich inhaltlich decken, macht sich anch theilweise wortliche Uebereinstimmong geltend; so beispielsweise in dem Satze: Supradicti rero Coloniensis archiepiscopus et comes cum ingenti armatorum multitudine ... advenientes requisiti per archiepiscopum, ducem et procuratorem predictos, ut iidem oppidum intrarent cum societate decenti de assignanda die ad electionem celebrandam . . . a ad hoc essent habiles nns cum ipsis tractaturi ... id facere contempserunt; derselbo stimmt theilweise wörtlich mit dem \&. Capitel unseres Berichtes. 
acceptirt worden; denn da sowohl Alfons als auch Richard die böhmische Stimme für sich in Anspruch nehmen durften, so kointe jede beider Parteien auf die Majorität im Kurcollegium hinweiseu und dies umsomehr, als von beiden Seiten die Legalität einzeluer Stimmen wegen rerhängter Excommunication (was bei Trier, Köln und dem Pfalzgrafen zutraf) bestritten werden konnte. Ist aber der Brief von 1263 auf Grund von Berichten beider Parteien entstanden, so ist wol auch die dem Sachsenspiegel entsprechende Anschauung vou der Siebenzahl der Wablfürsten diesen Berichten entnommen. Wir baben es also hier, sowie bei allen andern hier erwähnten Verfassungsgrundsätzen nicht mit den Anschauungen der Curie, sondern mit denen der beiden streitenden Parteien zu thun. Dies fällt aber für die Beurtheilung der Briefe Urbans von 1263 und ihrer Bedeutung für die deutsche Verfassung der Folgezeit schwer ins Gewicht'1). Ist es eine Eigenthümlichkeit des Briefes Urbau IV., neue Rechtsgruudsätze als längst giltige und geübte Gewohnheiten darzustellen, so ist doch im Auge zu behalten, dass der Papst nicht allgemein giltige Verfassungsgrundsäte aufstellen und sanctioniren will, dass er vielmehr nur objectiv darüber berichtet, was die beiderseitigen Gesandten vorbringen. Die Verkennung dieser Thatsache hat dazu geführt, dass man diesem Briefe eine viel zu grosse Bedeutang für die deutsche Verfassung beilegte. In Vorbringung solcher angeblich alter Rechtsgrundsätze leisteten besonders die Gesandten Richards viel; Urban bemerkt aber ausdrücklich, dass die Giltigkeit derselben von den Gesandten des Königs Alfous bestritten wurde ${ }^{2}$ ). Wie aus unserm Berichte hervorgeht, wählte aber auch Alfons diesen Weg der Beweisführung - alles was zu seinen Gunsten sprach, als alte Rechtsgewohnheit darzustellen. Davon also, dass der Papst dem Reiche neue Verfassungsgrundsätze aufoctroyirt habe, kann wenigstens bezüglich des Briefes von 1263 keine Rede sein, und so glaube ich demselben jede Bedeutung für die Weiterentwicklung der deutsshen Verfassung absprechen zu müssen ${ }^{3}$ ). Die Entwick-

1) Vgl. tiber die Briefe rom 31. August 1263 Busson Die Doppelwahl des Jahre 1257 S. $125 \mathrm{ff}$. nnd Harnack Kurfürstencollegium $259 \mathrm{ff}$.

8) Die Gesandten des Königs Alfons bestreiten nicht nur die von den Boten Richards behauptete Frcommunication des Erzbischofs von Trier, sondern auch consuetudinem quae de celebranda tempore vacantis imperii infra annum et diem regis Rom. electione praeponitur ac alias (scil. consuetudines). Von Seiten der castilischen Gesandten wird 1263 nur die Wabl in Frankfurt selbst als alter Gewohnheit gemäes bezeichnet; dergleichen melr wird in dem Berichte von 126 i angefuhrt. 3) Vgl. Harnack Kurfürstencollegium S. 55 und 260, der die Worte qui sunt septem numero kategorisch nennt, ohne zu bedenken, dass der Papst hier 
lung und Gestaltung der deutschen Reichsverfassung liegt in dieser Zeit einzig und allein in dem Kampfe der beiden Parteien, ron denen jede das als Verfassungsgrundsatz aufzustellen bestrebt ist, was zu ihren Gunsteu spricht. Eine förmliche Anerkennung der in dem Streben nach dem alleinigen Besitz der Krone von beiden Seiten aufgestellten Grundsätze hat überhaupt nicht stattgefunden, da es ja zu eiuer Entscheidung des bei der Curie angestrengten Processes nicht gekommen ist; denn nur in diesem Falle hätte der Papst zu den von den Parteien vorgebrachten angeblich uralten Verfassungsgrundsätzen eutschieden Stellung uehmen müssen.

Abgesehen von dem Verhältnisse dieses Berichtes zu dem Briefe Urbans, der ja die Hauptquelle für die Wahlvorgänge von 1257 bildet, liegt ein besonderer Werth desselben in den Artikeln, die sich über das Verhältniss des Königs Alfons zu Alexander IV. äussern.

In nomine domini amen. Iste sunt rationes propter quas magister R[udolfus] ${ }^{2}$ ) procurator excellentissimi domini A[lfonsi] dei gratia Romanorum, Castelle ac Legionis regis illustris semper augusti dicit, quod interest domini regis eiusdem se opponere petitioni domini $R$ [ichardi] comitis Cornubie et propter quas dicit, eundem comitem super petitione sua non esse aliquatenus audiendum et propter quas dicit, predictum dominum suum esse regem Romanorum et ipsum solum in imperio ius habere ac petitionem ipsius domini regis debere ad gratiam exauditionis admitti, cum ipse paratus sit omnes sollempnitates, que coronationem imperatoris precedere debent et observari consueverunt, plenissime adimplere.

In primis dicit idem procurator, quod die quam pars adversa dicit assignatam fuisse per quondam dominum Maguntinum archiepiscopum ad electionem Romani principis faciendam, IV principes electores videlicet bone memorie quondam $\mathbf{A}$ [rnoldus] Treverensis archiepiscopus, Boemie rex illustris, [Albertus] quondam dux Saxonie et [Johannes] marchio Brandaburgensis tum per se tum per procuratores ydoneos convenerunt et fuerunt presentes in oppido Franchenfurd.

Item quod dicti principes existentes in dicto loco, ut dictum est,

nur die Aussage der englischen Gesandten wiedergibt. Dieser Brief eignete sich deshalb auch ganz und gar nicht dazu, um aus ihm etwa, Regeln für die Folgezeite abzuleiten. Auch Schwabenspiegel LR. 130 kann nicht direct auf den Brief von 1268 zurückgehen.

a) Die Namen, welche entweder durch die Anfangsbuchstaben bezeichnet oder durch zwei Punkte angedeutet sind, wurden von mir ergănat.

Mittheilangen VI. 
fideles nuntios suos ad quondam [Conradum] Coloniensem archiepiscopum et [Ludoricum] comitem palatinum Reni eundemque ducem Bavarie, contra morem et consuetudinem principum et imperii castrametatos cum exercitibus suis et maxima multitudine armatorum in campis per tria miliaria a dicto oppido distantes ad minus, concorditer destinarunt, rogantes, monentes et requirentes eosdem ac plenam eis securitatem et fidantiam offerentes, quod ipsi ut principes pacifici et cum decenti comitiva venirent et villam intrarent ac convenirent in debito loco cum eis ad habendum simul in omni sinceritate et pace de principis electione et ordinatione tractatum, si tamen habiles erant ad tantum negotium prosequendum.

Item quod dicti duo principes scilicet Coloniensis archiepiscopus et comes palatinus Reni idemque dux Bavarie ${ }^{b}$ ) huiusmodi requisitionem, preces, monita ac securitatem et ipsos penitus contempserunt et venire ad eos contumaciter recusarunt.

Item quod ista omnia nota et notoria sunt ecclesie et toti regno Alemanie et de hiis est publica et consentiens fama in curia, Alamania et omnibus partibus christianitatis.

Item quod dicti IV principes, qui tum per se tum per procuratores in predicto castro de Franchenfurd convenerant, ut est dictum. ittendentes quod prefati Coloniensis et comes in castro cum eis convenire nolebant, ordinaverunt, statuerunt et concorditer assignarunt peremptorium terminum ad electionem principis in eodem loco de Franchenfurd secundum deum et iustitiam faciendam.

Item quod huiusmodi assignationem et ordinationem termini, ut est dictum, in dicto loco nox sollempniter publicarunt.

Item quod ad superbabundantem cautelam et dictorum duorum principum malitiam superandam denuntiaverunt eisdem assignationem dicti termini, publice requirentes et citantes eosdem ac etiam Maguntinum archiepiscopum, ut in eodem per ipsos termino ordinato in loco solito et debito convenirent cum eis ad electionem principis canonice celebrandam, si tamen habiles erant ad tantum et tale negotium prosequendun.

Item quod predicta omnia tunc pervenerunt ad notitiam et scientiam dictorum archiepiscopi Coloniensis et comitis palatini Reni ac etiam archiepiscopi Maguntini.

Item quod ista omnia nota et notoria sunt et de eis est publica et consentiens fama per totam Alamaniam.

b) comes palatinus Reni idemque .. dux Bavarie Cod.; im weitern Verlaufe aber comes palatinus Reni idemque dux Bavarie, also ohne die beiden Punkte zu setren. 
Item quod tempore $q u 0^{\circ}$ ) dicti Coloniensis et comes palatinus Reni idemque dux Bavarie se electioni seu nominationi domini $\mathrm{R}$ [ichardi] comitis Cornubie ingessisse ") dicuntur, erant excommunicati tam a canone quam ab homine.

Item quod bone memorie quondam dominus P[etrus] Capotius sancti Georgii ad velum aureum diaconus cardinalis, tunc in Alamania apostolice sedis legatus, ante electionem, que de dicto comite R[ichardo] facta asseritur, pro gravibus et manifestis iniurïs et offensis sibi per Coloniensem archiepiscopum in contemptum et derogationem ecclesie nequiter et publice irrogatis excommunicavit et denuntiavit pablice excommunicatum dictum archiepiscopum Coloniensem ${ }^{\mathrm{e}}$ ).

Item quod ista certa sunt et notoria in Alamania ac etiam in curia Romana et erant tunc temporis.

Item quod idem dominus cardinalis tempore predecessoris vestri quondam domini $\mathrm{A}$ [lexandri] apud Viterbium in sollempni et pablico consistorio, dum de isto imperiali negotio ageretur, coram eodem predecessore vestro et fratribus, presente etiam utraque parte, publice protestatus fuit, dixit et asseruit, quod idem archiepiscopus excommunicatus fuerat et erat tam a canone quam ab homine pro manifestis iniuriis et offensis, quas sibi et ecclesie irrogarat.

Item quod idem archiepiscopus postmodum per nuntium vel nuntios quos ad sedem apostolicam destinarit, et petiit et procurarit, se a dicta excommunicatione absolvi.

Item quod pro satisfactione iniuriarum et offensarnm illatarum predicto domino cardinali pro quibus excommunicatus erat, ut dictum est, et obtinenda absolutione solvit ipse vel alius pro eo duo milia marcarum, quas post dicti cardinalis obitum eius fideicommiłsarii receperunt.

Item quod comes palatinus Reni dux Bavarie erat tunc publice excommunicatus pro eo quod in contemptum et lesionem ecclesie adhesit, publice auxilium, consilium et favorem impendit quondam domino Frederico imperatori et domino regi Conradof f) filio suo ante et post sententiam latam contra dictum dominam imperatorem in concilio Lugdunensi.

Item quod in huiusmodi pertinatia perseveravit et contempsit claves per XII annos et plures.

Item quod habebatur in Theotonia ab omnibus excommunicatus et inimicus ecclesie manifestus.

c) quod Cod. d) Cod. e) Deber die Excommunication 8. Ennen Goschichte der Stadt Köln 2, 121 . ๆ conB. Cod. 
Item quod dicti duo principes excommunicati, conventione prius habita cum illis qui fuerunt huiusmodi factionis eorum solliciti, proxenere predictan electionem seu nominationem, que de domino comite R[icharlo] facta dicitur, interventu pecunie acceptate $¥$ ).

Item quod pro huiusmodi electione seu nominatione quilibet eorum recepit magnam pecunie quantitatem.

Item quod in Alamania, Francia, Anglia, Italia et per alias partes christianitatis publica et consentiens fama est quod per pecuuiam hoc fecerunt.

Item quod in oppido Frankenfurd fuit et est capella sollempnis et famosa, in qua consueverunt electores principes convenire ad habendum de electione tractatum et etiam ad electionem canonice celebrandam.

Item quod eo tempore quo einsdem comitis electio seu nominatio facta proponitur, [Gerhardus] quondam Maguntinus archiepiscopus in carcere et potestate ducis de Bronsvich detinebatur captivus.

Item quod pro consensu vel assensu, quem in facto dicti comitis idem archiepiscopus dicitur prestitisse, recepit ipse rel alius pro eo ex conventione prius habita magnan pecunie quantitatem; et de hoc est publica et consentiens fama in Alamania et est notum et notorium.

Item quod idem Maguntinus archiepiscopus specialem nuntium cum litteris suis misit in Ispaniam ad dominum regem, per quos de electione que facta dicebatur de domino comite $R$ [ichardo] se multis causis et rationibus excusabat, inter alia signiäcans et offerens domino regi, quod recognoscebat eum verum dominum et regem suum et quod ei in Theotoniam venienti paratus erat tamquam regi et domino obedire; et quod rogabat eum quod sibi cordi esset ulcisci iniuriam per ducem de Bronsvich sibi et ecclesie sue illatam h).

Item quod dicit et proponit dictus procurator regis Romanorum, Castelle ac Legionis illustris, quod dicti IV principes catholici et fideles, videlicet bone memorie quondam Treverensis archiepiscopus, Boemie rex illustris, murchio Brandeburgensis et dux Saxonie, adveniente predicto termino per eos, ut dictum est, ad electionem celebrandam statuto, predictis duobus principibus et Maguntino minime comparentibus set in perfidia et contumacia sua perseverantibis, couvenientes in loco debito et statuto tum per se tum per alios seu alium, servatis omnibus consuetudinibus et sollempnitatibus Romani imperii que solent et debent serrari in electione Romani principis,

s) acceptar. Cod. b) Am 16. August 1259 scheint Gerhard noch auf Seite Richards zu stehen, vgl. Ficker Reg. 5354; der Abfall kann also erst nach der Abreise Richarda nach England Ende 1258 oder 1259 erfolgt sein. 
Ein Bericht über d. Ansprüche d. Konigs Alfons a. d. deutschen Thron. 101

habentes ante oculos per litteras apostolicas eisdem iam presentatas apostolice sedis consilium et mandatum ${ }^{i}$ ) predictum dominum regem Castelle ac Legionis illustrem in Romanorum regem, promovendum in imperatorem concorditer et canonice elegerunt, sicut in decreto electionis ipsius et litteris priucipum ipsorum apertius continetur.

Item quod electionem ipsan cum ingenti gaudio, sicut fieri debuit sollempniter publicarunt.

Item quod dicti IV principes predictam electionem de domino rege canouice celebratam recoguoverunt et approbaverunt, tamquam legitimam et ratam et firmam habuerunt et iuraverunt predicto domino regi obedire et assistere tamquam gloriosissimo Romanorum regi et futuro imperatori ac domino suo.

Item quod dicti IV principes electionem et concordiam eorum de dicto domino rege canonice celebratam per sollempnes officiales imperii videlicet Spirensem episcopum cancellarium imperii et alios magnos et venerabiles viros clericos et laicos, nuntios et procuratores eorum, tunc in Yspaniam venientes predicto domino regi devotissime presentarunt, eidem ex parte principum, prelatorum, nobilium et universitatum Theotonie, quorum etiam in quantitate maxima scripta et litteras presentarunt, humiliter supplicantes quod electioni haiusmodi, que a deo et previa apostolice sedis ordinatione cesserat consentiretk).

Item quod idem dominus rex de matris ecclesie favore confisus cum favore et consilio domini regis Francie et fratrum suorum, de consilio etiam regum Aragonie, Navarre, Portugalie et aliorum multorum principum et nobilium christianitatis, deliberato etiam suorum consilio, canonice electioni de se facte consensit et negotium istud assumpsit imperii.

Item quod multorum principum, nobilium, civitatum et aliarum terrarum imperii iuramenta fidelitatis et possessionem eorum recepit per nuntios, officiales et vicarios suos, quos consulte per diversas partes Theotonie et alias ordinavit et misit ${ }^{l}$ ).

Item quod multos principes, nobiles et magnates Alamanie ad eum tamquam ad dominum suum devote in Yspaniam venientes cum vexillis et aliis sollempnitatibus iuxta morem imperii observandis de feudis, honoribus et iurisdictionibus, que ab imperio tenent sollempniter investivit et recepit $a b$ eis fidelitatis debite iuramenta.

Item quod dominus rex, sicut fieri debuit et processit, de voluntate et consilio suorum principum per nuntios suos et dictorum

i) Damit, ist der Brief Alexander IV. von 1256 Juli 28 (Potthast Reg. 16506) gemeint. k) Deber die Gesandtschaft vgl Ficker Reg. 5488 c. 1) Das wenige, was darüb:r bekannt ist, bat Busson Doppel wahl S. 65-68 zusammengestellt. 
principum cum suis ad sedem apostolicam accedentes hec omnia per electionis sue decretum, litteras et scripta principum electorum et alia publica munimenta predecessori vestro qnondam domino $A$ [lexandro] et fratribus suis nuntiare curavit.

Item quod predicta decretum, scripta et littere fuerunt exhibita, ostensa et lecta coram eodem predecessore vestro et fratribus suis in publico consistorio in civitate ista Viterbiensi, presente etiam parte adversa $\mathrm{m}$ ).

Item quod per eosdem nuntios suos et principum tunc et per alios successive pluries et quam pluries et demum per virum egregium fratrem suum dominum Emanuelem et alios sollempnes nuntios cum eo ad sedem apostolicam destinatos predicto predecessori et fratribus suis humiliter supplicavit, ut eidem invocando eum et inveniendo ac prosequendo ecclesie matris sue deberent favorem impendere, sicut temporibus retrohactis principibus Romanis per ecclesiam fieri consuevit.

Item quod ipse per nuntios et procuratores suos predictos et alios coram eodem predecessore ac domino Urbano, alio predecessore vestro, et fratribus vestris semper obtulit, se paratum ad veniendum et ad istud negotium efficaciter prosequendum ${ }^{n}$ ).

Item quod processit et fuit de consilio suorum principum ac nuntiorum et procuratorum ipsorum et multorum prelatorum et nobilium, qui ad eum de Theotonia in Yspaniam accesserunt quod, electione de eo canonice celebrata, ipse scriberet et intitularet se regem Romanorum semper augustum et ut rex omnia licenter et libere exerceret, et peteret a sede apostolica se vocari et einsdem sedis in prosecutione imperialis negotii suisque processibus auxilium, consilium et favorem, quia ista sicut petere et facere sibi de iure et consuetudine imperii competebant ${ }^{\circ}$ ).

Item quod olim apud Anagniam cum idem rex per nuntios suos ad hoc specialiter destinatos dicto predecessori vestro domino A[lexandro] et fratribus suis suum ad partes imperii nuntiasset adventum et quod paratus erat et in omnem eventum venire rolebat - propter quod eius requirebat consilium et favorem -, idem predecessor de fratrum consilio eisdem nuntiis expresse responditp), quod nolebat eum venire, dis-

m) In Viterbo hielt sich Alexander IV. 1257 Mai 28 bis 1258 Oct. 20 auf; die Gesandtschaft gehört wol erst in das Jahr 1258. p) Vgl. dazu Potthast Reg. 18272 und Böhmer Reichssachen 86. $\quad$ ) Den Titel electus, den Alfons seit seiner Wahl in Pisa 1256 Mărz 18 fủhrte, liess Alfons nun fallen. Absichtlich wird ignorirt, dass Urban IV. 1268 den Titel electus beiden Bewerbern zuerkannt hatte. p) rexpondit $\operatorname{cod}$. 
Ein Bericht über d. Ansprüche d. Königs Alfons a. d. deutwohen Thron. 103

suadebat ei, deortabatur eum, etiam si venire promisisset, etiam si iurasset $q$ ).

Item quod ista responsione non contentus idem predecessor super hoc litteras apostolicas et specialem ac sollempnem ad eum nuntium destinavit, videlicet reverenlum patrem dominum G[ottefridum] sancti Georgii ad velum aureum diaconum cardiuslem tunc capellanum suum.

Item quod idem predecessor respondens ad ea que proposita fuerunt per dominum Emanuelem fratrem domini regis et alios qui cum eo al sedem apostolicam accesserunt, dixit se missurum in contiuenti ad dominum regem nuntium sedis apostolice specialem, qui eidem ex parte sedis eiusdem ad omnia et singula per eum proposita verbotenus responderet.

Item quod quondam dominus Andreas de Ferentino, domini pape cappellanus, post dominum Emanuelem in Yspaniam e vestigio veniens, presentatis litteris apostolicis, lomino regi dixit et retulit ea ex parte domini pape: quod placeret ei supersedere et expectare, quia intentionis domini pape et fratrum erat super negotio isto ad honorem sunm salubriter providere, et quod pro constanti teneret et certus esset quod dominus papa numquam dederat nec dare intendebat domino comiti $R$ [ichardo] in negotio isto favorem in preiudicium vel lesionem iustitie vel honoris domini regis in aliquo.

Item quod idem predecessor requisitus a predicto domino $\mathrm{E}[\mathrm{ma}-$ uuele], fratre domini regis, et aliis qui cum eo ad sedem apostolicam venerant, si per nuntios vel litteras in Theotonia ullum dicto comiti mandaverat dari farorem, respondit: absit fli, quia numquam dedimus nec mandarimus dari nec dare intendimus nec aliquid facere per quod karissimi filii nostri fratris tui regis illustris honori in aliquo derogetur, et quod fratrem Gualterium Anglicum ad hoc non miserat; et si forte ipse dominum regem Castelle super negotio imperii in aliquo in Alamania offendisset, ita graviter puniret eum, quod pena eius esset aliis ad terrorem $r$ ).

Item quod in omnibus nuntiis et procuratoribus qui super isto negotio pro parte domini regis ad curiam accesserunt, semper de non dando favorem predicto comiti $\mathrm{R}[\mathrm{ichardo}]$ patenter et expresse predecessor idem respondit.

Item quod est de approbata consuetudine iurium et privilegiorum

a) Vgl. auch Potthast 18272 und Ficker Reg. 5518. In Anagni weilt Alexander mit einer kurzen Unterbrechung von 1258 Oct. $\$ 1$ bis 1260 Nov. 6. In einem Briefe vom 16. Juni 1259 spricht Alfons von seiner Absicht, ins Reich zu kommen (Ficker Reg 5503). I) Ueber Gualterius de Rogate und die offenbare Begünstigung Richards s. Potthast Reg. 17512, 17549 und Ficker Reg. 5349. 
Germanorum quod nullus in imperatorem possit vel debeat eligi vel promoveri qui alterius imperio seu dominio sit subiectus seu alterius sit vassallus. notoria.

Item quod de hiis omnibus est publica fama et sunt publica

Predicts vel que sufficiant de predictis et alia que faciunt et facere possent ad intentionem et defensionem predicti domini regis et iuris eiusdem, poterunt probari, si opus est, in Alamania, Ytalia, Yspania, in regno Francie et in curia Romana; protestatur tamen et dicit idem procurator, quod non astringit se ad viam specialem probationis, set predicta omnia poterunt probari per confessionem partis adverse, instrumenta, litteras et testes ac indicia cetera, que a iure non respuentur infra dilationes magnitudini, gravitati, qualitati et quantitati tanti et talis negotii congruentes.

Et protestatur idem procurator et dicit quod liceat adhuc domino regi, qui plenius novit factum istud et processum eiusdem ac omnia et singula que in eo acta et gesta sunt, alios dare articulos et probare ad intentionem et defensionem suam et sui iuris et iusticie, presertim cum idem dominus rex iuxta formam citationis predecessoris vestri et restre eum non potuerit ad plenum instruere in predictis. 